\title{
Topographic location and branching pattern of the superior mesenteric artery with its clinical relevance: a cadaveric study
}

\author{
S. Nigah ${ }^{1}$, A. Patra ${ }^{1}$ (D) S. Chumbar², P. Chaudhary ${ }^{1}$ \\ ${ }^{1}$ Department of Anatomy, All India Institute of Medical Sciences, Bathinda (PB), India \\ 2Department of Forensic Medicine, GGS Medical College, Faridkot, India
}

[Received: 7 January 2021; Accepted: 22 February 2021; Early publication date: 22 March 2021]

Background: The topographic location of the superior mesenteric artery (SMA) and its branching pattern are usually arbitrary in textbooks. This study, therefore, aims to provide topographic information of SMA with reference to the vertebral bodies, ventral branches of aorta and branching pattern of SMA.

Materials and methods: The study was conducted on 35 embalmed adult human cadavers. We performed detailed dissection of the SMA to topographically locate its origin in respect to vertebral level and other ventral branches of the abdominal aorta. We have categorised the branching pattern of SMA into three different types depending upon the number of arterial pedicles, traced from proximal to distal to look into their anastomoses and formation marginal artery of Drummond. Results: Vertebral level of origin of SMA varied between the lower third of twelfth thoracic vertebra (T12) and lower third of first lumbar vertebra (L1), most commonly arose at the level of the lower third of $L 1$ (77.14\%). The average distances between the origin of SMA and coeliac trunk (CT), inferior mesenteric artery (IMA) and aortic bifurcation were $1.84 \mathrm{~cm}, 6.67 \mathrm{~cm}$ and $10.39 \mathrm{~cm}$, respectively. Depending on the branching pattern, type $A$ was found in 29 (82.85\%) cases, type $B$ in 5 (14.28\%) and type $C$ in 1 (2.85\%). In 2 cases (both of type $B$ ), the marginal artery was incomplete.

Conclusions: The most common topography of origin of the SMA was opposite the lower third of L1. The coeliac-superior mesenteric relationship was most consistent than between any other two points on the abdominal aorta; $85 \%$ of the SMAs were concentrated within a space of $1.00 \mathrm{~cm}(0.60-1.50 \mathrm{~cm})$ from the CT. Type A branching pattern was most commonly seen in our study population. (Folia Morphol 2022; 81, 2: 372-378)

Key words: aortic bifurcation, coeliac artery, inferior mesenteric artery, superior mesenteric artery, topography

\section{INTRODUCTION}

Three unpaired arteries arise from the ventral surface of the aorta, coeliac trunk (CT), superior mesenteric artery (SMA) and inferior mesenteric artery (IMA). The branches arising from these three arteries solely cater the derivatives of foregut, midgut and hindgut, respectively [20]. Usually, SMA originates from the anterior surface of the aorta $1 \mathrm{~cm}$ below the $\mathrm{CT}$, at the level of the L1/2 intervertebral disc, posterior to the body of the pancreas. It then descends abruptly

Address for correspondence: Dr. A. Patra, Ass. Prof., Department of Anatomy, All India Institute of Medical Sciences, Bathinda (PB), India, tel: +91-8580481455, e-mail: apurba.cnmc03@gmail.com

This article is available in open access under Creative Common Attribution-Non-Commercial-No Derivatives 4.0 International (CC BY-NC-ND 4.0) license, allowing to download articles and share them with others as long as they credit the authors and the publisher, but without permission to change them in any way or use them commercially. 
downwards anterior to the left renal vein, the uncinate process of the pancreas and the horizontal part of the duodenum, and runs within the root of the mesentery of the small intestine up to the ileocecal junction in the right iliac fossa. Here it ends by giving branches to the ileum and form an anastomosis with a branch of the ileocolic artery in most of the cases [17]. The artery gives off several branches which include; the inferior pancreaticoduodenal artery from the posterior aspect, jejunal and ileal branches from the left surface and middle colic, right colic and ileocolic branches from the right surface [26]. The colic branches of SMA (right colic, middle colic and ileocolic) anastomoses with each other and with the colic branch of IMA (left colic) to form the marginal artery of Drummond which supplies the large gut. Discontinuous marginal artery due to the failure of the anastomosis $[2,16]$ may lead to infarction injury to the colon. Left colic flexure is the most common site of such vascular injury. Topographical features of the ventral aortic branches including SMA have been reported, to a limited extent. The values given in the standard textbooks are usually arbitrary and no degrees of variation mentioned. With such background, the present study was undertaken to provide statistical information on the points of origin of the SMA with reference to the level of vertebral bodies and intervertebral discs, inter distances between the origin of SMA and the CT, inferior mesenteric Artery and aortic bifurcation. Anatomical knowledge regarding the branching pattern of SMA is very crucial for operating surgeons while mobilising them during surgery. Unfortunately, very few studies are available on this issue. So, we aimed to study its branching pattern, the formation of anastomotic chain between them in relation to the supplying area prone to infarction injury of the colon and categorise the findings accordingly.

\section{MATERIALS AND METHODS}

Thirty five adult cadavers of north Indian origin and aged between 45 to 65 years with a mean age of $55.84 \pm 7.74$ years were examined in this study. The relatively small number of females (5) in the study sample did not call for separate records on sex differences. The cadavers were obtained from the gross anatomy dissecting room of the Department of Anatomy. Dissection carried out after ethical approval was obtained from the Institutional Ethical Committee. The cadavers were of north Indian origin and formalin embalmed. A midline incision was given starting from the xiphoid process to symphysis pubis. Skin and fascia were reflected laterally following the method of Cunningham's practical manual for dissection [18]. The greater omentum, coils of small intestine with its mesentery and large intestine were identified. The transverse colon with greater omentum was reflected superiorly over the costal margin to get a better and clear view of the coils of the small intestine. The coils of the jejunum and ileum were seen attached firmly to the posterior abdominal wall through the root of the mesentery. These coils were reflected laterally and moved to the left side of the abdomen without undue stretch so that the right side of the mesentery faces anteriorly. Peritoneum on the right side of the mesentery was removed to expose the branches of SMA. SMA was seen lying along the root of the mesentery and branches arising from it were distributed between the two layers of the mesentery to supply the coils of the intestine. Once the routine dissection of the abdomen was advanced sufficiently to dispose the abdominal aorta and its branches, a pin with a small head was inserted into the vertebral column through the centre of the origin of each unpaired visceral branch and also at the level of bifurcation of the abdominal aorta into the common iliac arteries. The pins were hammered into the vertebral column very carefully to insert the pin in the transverse plane and to avoid the error of an oblique insertion. The distance between the four pins was then measured using digital vernier callipers (Mitutoyo $12 " / 300 \mathrm{~mm}$, Japan) with least count of $0.01 \mathrm{~mm}$ and recorded as inter arterial distances. The measurements were taken from the centre of one pin-head to the centre of the next pin-head (Fig. 1). The measurements were repeated 3 times by the same observer and the mean was taken as final for further analysis. The inter arterial distances thus obtained were statistically analysed using the Microsoft Office Excel software version 16.0 for Windows 10.

Superior mesenteric artery with its branches was traced from proximal to distal up to the level of formation of marginal artery of Drummond. Depending upon the number of arterial pedicles, Mane and Shinde [13] categorised the branching pattern of SMA into three types. In the present study, we followed the same classification of branching pattern:

- type A: usual pattern with three arterial pedicles. middle colic artery (MCA), right colic artery (RCA) and ileocolic artery (ICA) arising independently; 


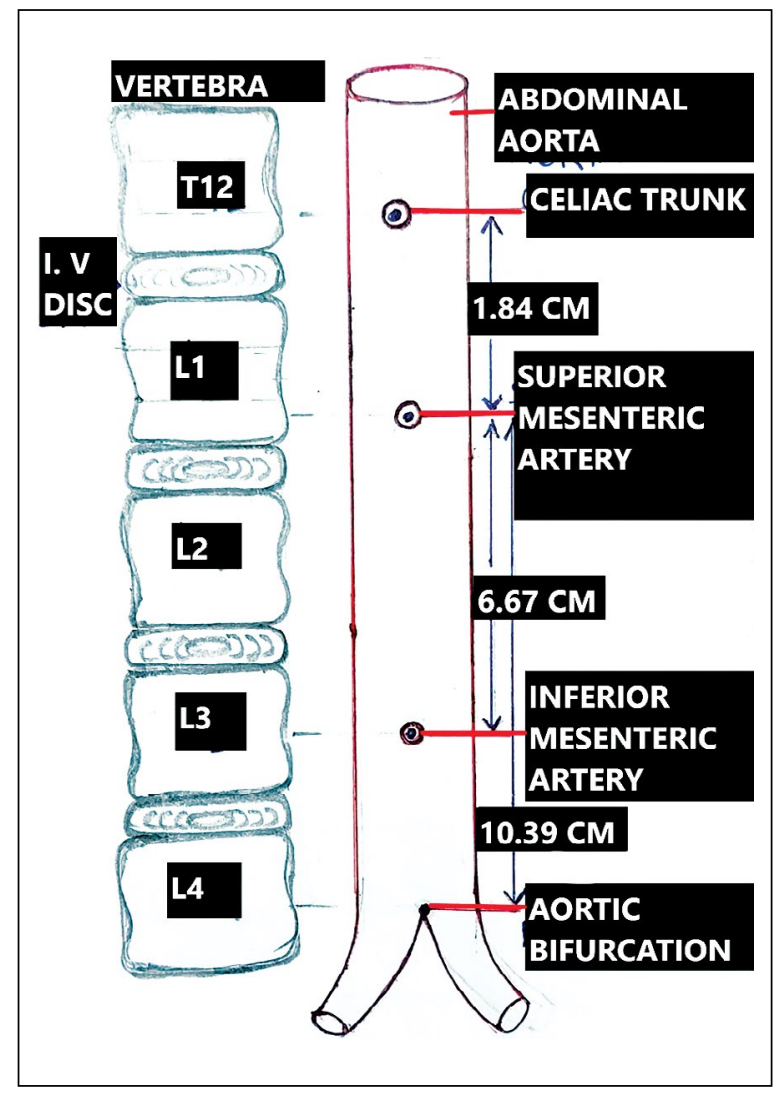

Figure 1. Location of the unpaired ventral branches of the abdominal aorta and its bifurcation in relation to the vertebral bodies and measurements of inter arterial distances. The average distances between the origin of superior mesenteric artery and coeliac trunk, inferior mesenteric artery and aortic bifurcation were $1.84 \pm 0.43 \mathrm{~cm}$, $6.67 \pm 1.13 \mathrm{~cm}$ and $10.39 \pm 1.23 \mathrm{~cm}$, respectively.

- type B: two arterial pedicles. MCA and RCA arising as a common stem;

- type C: two arterial pedicles. The common stem of MCA and RCA with branches of MCA arise individually.

After documenting the branching pattern, the abdominal viscera were removed and the abdominal aorta was stripped off from the front of the vertebral column, the vertebral level of the second pin determining the level of origin of SMA was recorded in relation to the vertebral body. The twelfth rib was identified and traced medially to identify the T12 vertebra and thus subsequent vertebral levels in the cadaver. To locate the origin of the SMA in accordance to the vertebral level, the vertebral bodies were divided into upper, middle and lower thirds and the intervertebral discs were considered equivalent to the height of the one-third of a vertebral body.

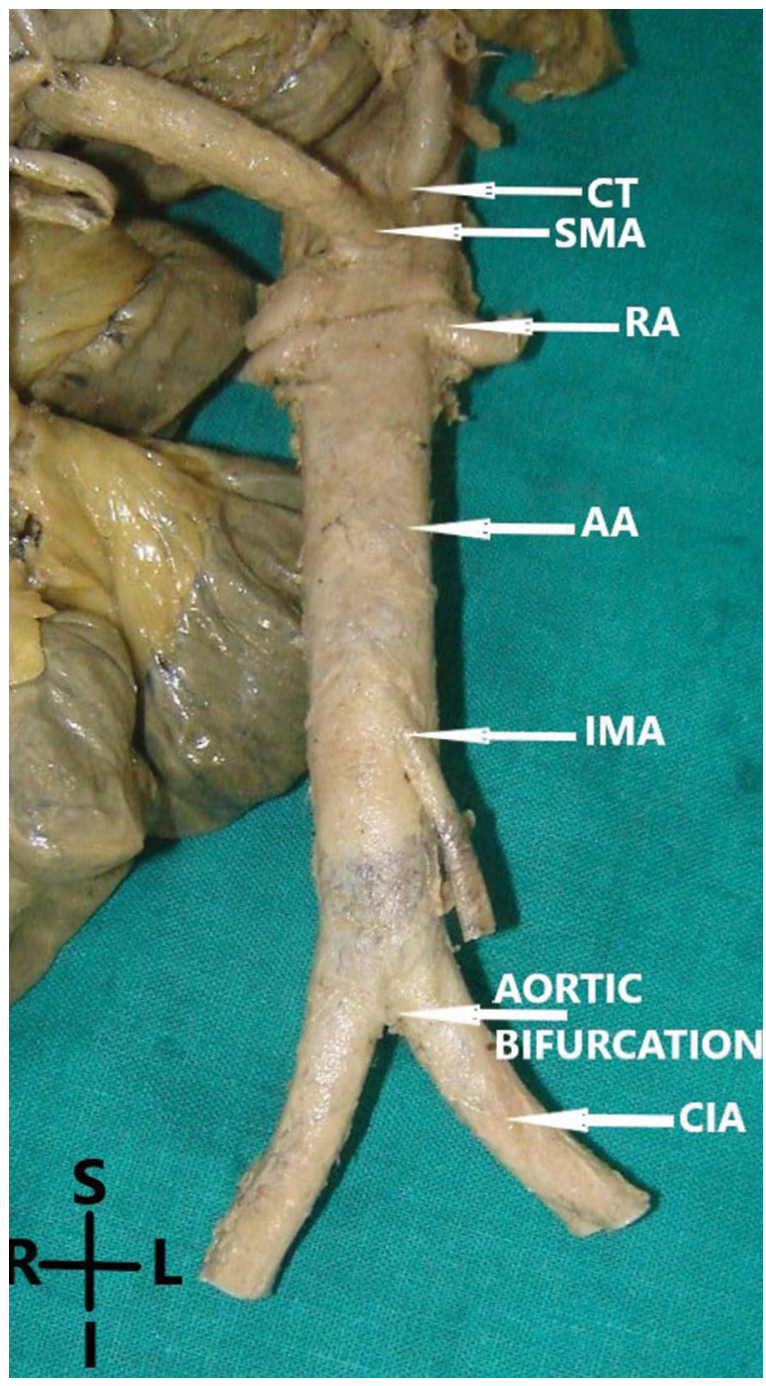

Figure 2. Chronology of emergence of ventral branches from aorta with close approximation of coeliac trunk (CT) and superior mesenteric artery (SMA); RA — renal artery; AA — abdominal aorta; IMA — inferior mesenteric artery; CIA — common iliac artery.

\section{RESULTS}

In the present study, a total of 35 human cadavers aged 45 to 65 years were dissected. SMA with its branches was studied to identify the topographic location of SMA and its branching pattern.

In all the cadavers, SMA was seen arising from the abdominal aorta as a separate ventral branch and coeliac-mesenteric trunk (CMT) was absent. In two specimens there was a close approximation (inter arterial distance $<0.05 \mathrm{~cm}$ ) of coeliac and superior mesenteric vessels, but their topographical integrity was not hampered as they emerged from the aorta (Fig. 2). Chronologically, SMA was $2^{\text {nd }}$ in origin in all the cases after the origin of CT. 


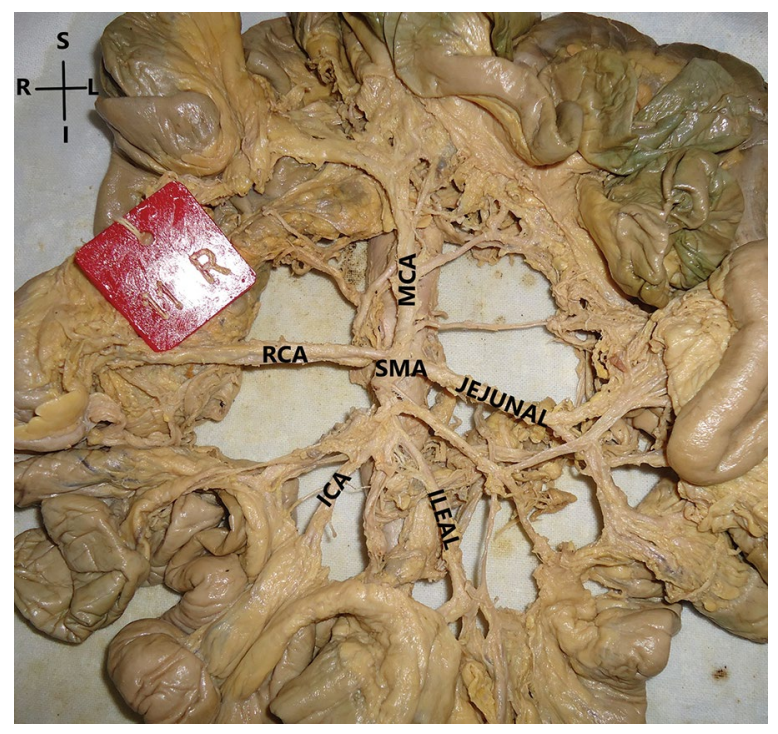

Figure 3. Type A: usual pattern with three arterial pedicles. Middle colic artery (MCA), right colic artery (RCA) and ileocolic artery (ICA) arising independently from the aorta (specimen no: 11R).

Vertebral topography of origin. The origin of SMA was studied in respect to the vertebral level of thoracolumbar region and ranged between the lower third of T12 to lower third of L1 vertebra, a spread of 5 intervals (4 vertebral thirds and 1 intervertebral disc). In 27 (77.14\%) cases it was arising at the level of the lower third of $L 1$, in $5(14.28 \%)$ cases at the upper third of L1 and in $3(8.57 \%)$ cases at the lower third of T12. So, the mean level of origin was opposite the lower third of L1.

Inter arterial distance of origin (in $\mathrm{cm}$ ). Measurements were taken to document the distances of the site of origin of SMA from CT, IMA and bifurcation of the aorta.

- inter-distance between SMA and CT: the mean distance between SMA and CT was found to be $1.84 \pm 0.43 \mathrm{~cm}(1.30-2.10 \mathrm{~cm})$. Two $(5.71 \%)$ cases were found in close approximation (distance $\leq 0.5 \mathrm{~cm}), 30(85.71 \%)$ cases concentrated between $0.60 \mathrm{~cm}$ and $1.50 \mathrm{~cm}$ and in $3(8.57 \%)$ cases it was more than $1.50 \mathrm{~cm}$;

- between SMA and IMA: points of origin ranged from $4.30 \mathrm{~cm}$ to $8.00 \mathrm{~cm}$; the mean interval was $6.67 \pm 1.13 \mathrm{~cm}$, there was a marked concentration of the variates (34\%) between $5.60 \mathrm{~cm}$ to $6.50 \mathrm{~cm}$ followed by a space of $2.50 \mathrm{~cm}(5.50 \mathrm{~cm}$ to $8.00 \mathrm{~cm}$ );

- between SMA and aortic bifurcation: SMA ranged from $8.30 \mathrm{~cm}$ to $11.90 \mathrm{~cm}$ above the bifurcation; the mean interval was $10.39 \pm 1.23 \mathrm{~cm}$.

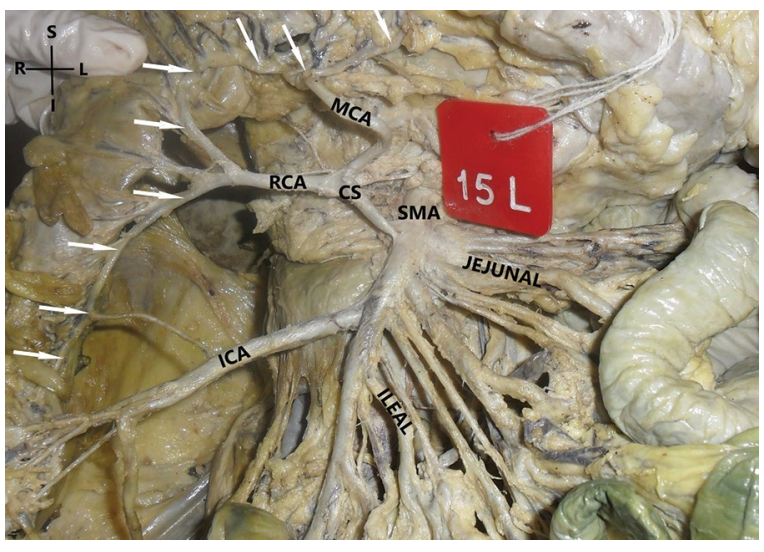

Figure 4. Type B: two arterial pedicles. Middle colic artery (MCA) and right colic artery (RCA) arising as a common stem (CS). Arrows showing the formation of marginal artery of Drumond by anastomoses among the branches of ileocolic artery, RCA and MCA (specimen no: 15L).

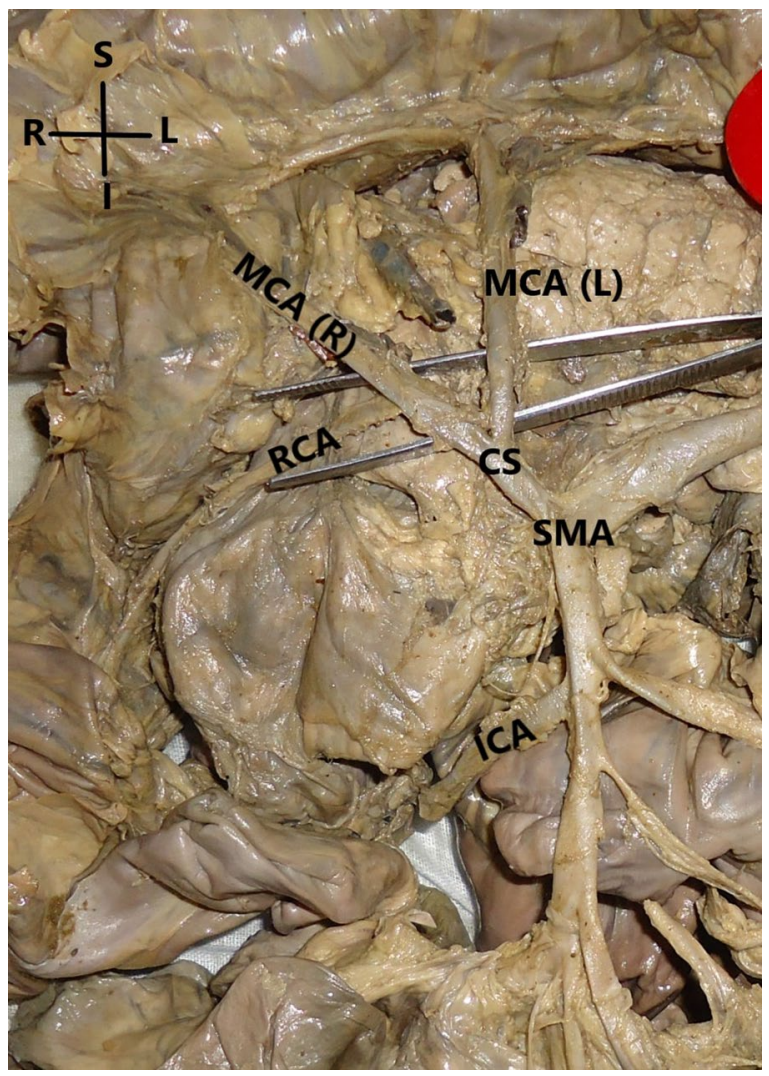

Figure 5. Type C: two arterial pedicles. Common stem of middle colic artery (MCA) and right colic artery (RCA) with branches of MCA arise individually and RCA arises from one of the branches of MCA (right branch of MCA).

Branching pattern. Pattern of distribution was categorised into three different types depending upon the number of arterial pedicles. type A (Fig. 3) 
was found in $29(82.85 \%)$ cases, type B (Fig. 4) in $5(14.28 \%)$ and type C (Fig. 5) in $1(2.85 \%)$. In most of the cases, the anastomotic chain was completely formed except in 2 cases (type B) where the left branch of MCA did not reach up to the left colic flexure, thus failed to anastomose with the ascending branch of the left colic artery (Fig. 4).

\section{DISCUSSION}

Anatomical knowledge about the topographic location of SMA and its branches can help in preventing iatrogenic injuries during abdominal surgeries, specifically during laparoscopic procedures. Keeping in view the importance of the topographic location of SMA and its branching pattern, our observations were discussed and correlated with the study of earlier workers.

The abdominal vessels, especially the $\mathrm{CT}$ and the SMA, frequently show diverse anomalies in their origin and course; thus, these arteries are studied with great interest. Several anatomic and radiological studies have described the variations in origin of the ventral branches of the abdominal aorta [14]. CT and SMA may rarely arise as common trunk from the ventral surface of the abdominal aorta, called as the CMT. The incidence of CMT was reported to be low ranging from $0.40 \%$ to $2.70 \%$ [25]. No obvious cause of CMT was seen in any of the specimens, SMA was $2^{\text {nd }}$ in chronological order of origin from the abdominal aorta after CT.

In the present study, the vertebral levels of origin of SMA were found between the lower third of T12 and lower third of L1. In most of the cases (77.14\%) the point of origin of SMA was at the level of the lower third of $\mathrm{L} 1$, followed by the upper third of $\mathrm{L} 1$ $(14.28 \%)$ and lower third of T12 (8.57\%). The mean level of origin occurred opposite the lower third of $\mathrm{L} 1$. This level corresponded to that obtained by George [7] in the Canadian population and Heidsieck [8] in the German population. Adachi [1] and Taniguchi [24] found the mean vertebral level of origin of SMA at the middle third of L1. In all of these means cluster opposite the lower two-thirds of the L1. This was a sharp contrast with the findings of Corsy and Aubert [4] who gave the mean of location opposite the disc between the T12 and L1.

Kao et al. [10] studied 24 SMA angiograms to determine the level of origin of SMA. They found SMA to arise below the level of the pedicle of T12 in $4(16.60 \%)$ cases, above the level of the pedicle of
L1 in $4(16.60 \%)$ cases, at the level of the pedicle of L1 in $11(45.80 \%)$ cases and below the level of the pedicle of L1 in $5(21.00 \%)$ cases. So, the vertebral levels of origin of SMA are almost in consonance with our findings.

Topographic location of SMA in relation to the ventral branches of the aorta was studied by few authors. In most of the studies, the origin of the artery was located in relation to the $\mathrm{CT}$. In the present study, we have measured the distances between the origin of SMA and CT, IMA and bifurcation of the abdominal aorta to locate the SMA more consistently.

Superior mesenteric artery was found $1.84 \mathrm{~cm}$ distal to the $C T$ and the distance ranged from $1.30 \mathrm{~cm}$ to $2.10 \mathrm{~cm}$. whereas, in a study done by Songur et al. [21], the distance ranged from $1.20 \mathrm{~cm}$ to $1.60 \mathrm{~cm}$, almost in agreement with our study.

George [7] studied 94 cadavers in which the mean distance between SMA and celiac trunk was $1.6 \mathrm{~cm}$ ranging from $0.50 \mathrm{~cm}$ to $3.10 \mathrm{~cm}$.

Heidsieck [8] measured this distance in 98 cadavers and SMA was found $1.40 \mathrm{~cm}$ distal to the $C T$ and the distance ranged from $0.50 \mathrm{~cm}$ to $3.00 \mathrm{~cm}$. Such differences may be attributed to the method of study adopted by different authors, built of the cadavers understudy and ethnicity.

We found the inter-distance between the origin of SMA and IMA to be $6.67 \mathrm{~cm}$ ranging from $4.3 \mathrm{~cm}$ to $8.00 \mathrm{~cm}$ whereas, Songur et al. [21], found the distance ranging from $4.97 \mathrm{~cm}$ to $6.60 \mathrm{~cm}$. Heidsieck [8] examined 93 cadavers and found the mean inter distance to be $7.50 \mathrm{~cm}$ ranging from $5.00 \mathrm{~cm}$ to $10.00 \mathrm{~cm}$.

George [7] measured the distance between the origins of the SMA and IMA in 95 cadavers, the mean distance was $7.10 \mathrm{~cm}$, ranging from $4.20 \mathrm{~cm}$ to $10.30 \mathrm{~cm}$.

Very few works have reported the topographic location of SMA in relation to the aortic bifurcation. We found SMA $10.39 \mathrm{~cm}$ (range $8.30-11.90 \mathrm{~cm}$ ) proximal to the bifurcation. According to a case reported by Yoo et al. [27], the distance between SMA and bifurcation of the aorta was $12.50 \mathrm{~cm}$ and located at the level of the body of L1.

Comparing these inter arterial distances statistical$l y$, less variability was observed in the coeliac-superior mesenteric relationship than between any other two points on the abdominal aorta; $85.71 \%$ of the superior mesenteric vessels were concentrated within a small space of $1 \mathrm{~cm}(0.60-1.00 \mathrm{~cm})$ from the CT. 
In two instances, the CT and SMA arose in very close approximation $(<0.5 \mathrm{~cm})$, almost at the same level.

The coeliac arid SMAs have a striking consistency in topographic position in the adult human body. The low cervical origins in embryonic life and subsequent caudal "migration" during intrauterine development may be considered for such a phenomenon. Tandler [23] have shown that the arteries arising from the ventral aspect of the aorta to supply the stomach and intestines undergo progressive shifting in segmental levels until their definitive site have been reached. The coeliac artery migrates from a point opposite the fourth cervical nerve to the level of the $12^{\text {th }}$ thoracic segment. The superior mesenteric artery, from the $1^{\text {st }}$ thoracic to the $1^{\text {st }}$ lumbar segment; the inferior mesenteric, however, descends from the $12^{\text {th }}$ thoracic to the third lumbar segment. The adult levels are usually attained by the time the embryo is $17.00 \mathrm{~mm}$ in length. Thus, it is apparent that the final sites of these vessels are subject to variation. The striking differences in descent demonstrated by the coeliac and superior mesenteric arteries in contrast to the inferior mesenteric are readily explained by the proportionately greater alterations involving the upper part of the alimentary tract. Although the exact mechanism of this migration has not been established, Felix [6] believed that it was due to unequal growth of dorsal and ventral walls of the aorta, an actual shifting of the ventral branches when compared with the dorsal segmental vessels.

Depending upon the number of arterial pedicles we have divided SMA into three categories. We documented type $\mathrm{A}$ (three arterial pedicles) as the most common (79\%) pattern of arrangement. According to Decker et al. [5], three arterial pedicles (type A) was seen in $23.8 \%$, two arterial pedicles (type B) with RCA arose from the ileocolic seen in $22.70 \%$ and from MCA seen in $21.50 \%$ of cases. Igiri et al. [9], studied the pattern of distribution of branches of SMA in the Nigerian population. They had divided population into three groups:

- group A: classical three arterial trunks with 6-7 jejuno-ileal branches (60\%);

- group B: three arterial trunks with appendicular artery arising directly from ICA $(26.70 \%)$;

- group C: two arterial trunks with RCA from the ileocolic artery (13.30\%).

Nelson et al. [15] found that RCA and MCA arose separately from SMA in $34 \%$ and $58 \%$ of the cas- es, respectively. Whereas, in $40 \%$ RCA originated as a common stem.

Variations in the branching and distributions of the SMA are not uncommon phenomena $[3,11,15,19]$. Branches of SMA (MCA, RCA, ICA) anastomose with each other to form a continuous arterial chain, which sends twigs to supply the large intestine up to the level of the junction between the right $2 / 3^{\text {rd }}$ and left $1 / 3^{\text {rd }}$. If these branches fail to anastomose, then the continuity of the chain breaks and thus making large intestine prone to ischaemia. Igiri et al. [9], reported that the branches of RCA and ICA were not anastomosing in group $C$ pattern of SMA. This was similar to earlier researchers who also reported discontinuous marginal artery due to the ICA failing to anastomose with the RCA [14, 22]. In the present study, the marginal artery supplying the ascending colon up to the right colic flexure was continuous in all the cases.

Left colic flexure is very crucial (watershed region) regarding its arterial supply and more prone to ischaemic injury, as it receives dual blood supply from the terminal branches of SMA and the IMA. In the context of ischaemia, the splenic flexure is sometimes referred to as Griffith's point. Most of the authors believe that the left colic flexure is often poorly supplied as in this part the vascular continuity of the arterial arcades (Riolan's arcade) is usually interrupted [17, 18]. Contrary to what is believed by most authors, Lorenzini et al. [12] studied 2000 angiograms of mesenteric arteries and reported the left flexure to be very well supplied while the descending colon results to be poorly supplied.

Basmajian et al. [2] reported discontinuous marginal artery in about $50 \%$ of cases over splenic flexure due to failure of anastomoses between RCA (branch of SMA) and LCA (branch of IMA). According to Steward and Rankin [22], the RCA may originate from the MCA or ICA, and a large branch, the Arc of Riolan, may occasionally connect the stem of the SMA with the LCA on the posterior abdominal wall.

In the present study, we found two cases, both of type $B$ variety where the left branch of MCA failed to reach the LCA resulting in a discontinuous marginal artery. In such cases LCA serves as an end artery making the splenic flexure prone to ischaemic injury, especially accidental ligation/ cauterization of the small branches of LCA during hemicolectomy may make aggravate the situation. 


\section{CONCLUSIONS}

The mean location of the origin of the SMA was opposite the lower third of L1. Less variability was observed in the coeliac-superior mesenteric relationship than between any other two points on the abdominal aorta; $85 \%$ of the superior mesenteric vessels were concentrated within a space of $1.00 \mathrm{~cm}(0.60-1.50 \mathrm{~cm})$ from the $\mathrm{CT}$. Type $A$ branching pattern was most commonly seen in our study population. Variations in the branching pattern of SMA are clinically very important for laparoscopic surgeons and interventional radiologists to prevent iatrogenic injury to these vessels.

\section{Conflict of interest: None declared}

\section{REFERENCES}

1. Adachi B. Anatomie der Japaner I. Das Arterien system der Japaner. Band II Kaiserlich-Japanischen Universitätzu Kyoto, Kyoto Maruzen 1928: 20-71.

2. Basmajian JV, Slonecker CE. Mesenteric vessels, Duodenum, and Pancreas. Grant's Method of Anatomy. 11th ed. William \& Wilkins, Baltimore 1980: 172-173.

3. Benton RS, Cotter WB. A hitherto undocumented variation of the inferior mesenteric artery in man. Anat Rec. 1963; 145: 171-173, doi: 10.1002/ar.1091450208, indexed in Pubmed: 13967564.

4. Corsy E, Aubert A. Artères de l'intestin grêle et des colons. Bibliogr Anat. 1913; 23: 221.

5. Decker GAG, du Plesis DJ. Lee McGregor's: A Synopsis of Surgical Anatomy. 12th ed. Varghese Publishing House, Bombay : 226-228.

6. Felix W. In: Keibel F, Mall FP. Manual of human embryology. Vol. 2, Chapter 19. JB Lippincott Co., Philadelphia 1912.

7. George R. Topography of the unpaired visceral branches of the abdominal aorta. J Anat. 1935; 69(Pt 2): 196-205, indexed in Pubmed: 17104532.

8. Heidsieck E. Zur Skeletopie der grossen Äste der Bauchaorta. Anat Anz. 1928; 66: 6-24.

9. Igiri $A O$, Ekong $M B$, Egemba GO, et al. The pattern of arrangement and distribution of the superior mesenteric artery in a Nigerian population. Int J Morphol. 2010; 28: 33-36.

10. Kao G, Whittington R, Coia L. Anatomy of the celiac axis and superior mesenteric artery and its significance in radiation therapy. Int J Radial Oncol Biol Phys. 1993; 25(1): 131-134, doi: 10.1016/0360-3016(93)90155-o, indexed in Pubmed: 8416869.

11. Koizumi M, Horiguchi M. Accessory arteries supplying the human transverse colon. Acta Anat (Basel). 1990; 137(3): 246-251, doi: 10.1159/000146827, indexed in Pubmed: 2349869.

12. Lorenzini L, Bertelli L, Lorenzi M. La disposizione arteriosa nel territorio della flessura colica sinistra [Arterial supply in the left colonic flexure]. Ann Ital Chir. 1999; 70(5): 691-698, indexed in Pubmed: 10692789.

13. Mane D, Shinde D. A Morphometric study of superior mesenteric artery and its implication in laparoscopic Surgery. Int J Med Res Rev. 2015; 3(4): 372-377, doi: 10.17511/ ijmrr.2015.i4.070.

14. Michels NA, Siddharth $P$, Kornblith $\mathrm{PL}$, et al. The variant blood supply to the descending colon, rectosigmoid and rectum based on 400 dissections. Its importance in regional resections: A review of medical literature. Dis Colon Rectum. 1965; 8: 251-278, doi: 10.1007/BF02617894, indexed in Pubmed: 14323715.

15. Nelson T, Pollak R, Jonasson O, et al. Anatomic variants of the celiac, superior mesenteric, and inferior mesenteric arteries and their clinical relevance. Clin Anat. 1988; 1(2): 75-91, doi: 10.1002/ca.980010202.

16. Oran I, Yesildag A, Memis A. Aortic origin of right hepatic artery and superior mesenteric origin of splenic artery: two rare variations demonstrated angiographically. Surg Radiol Anat. 2001; 23(5): 349-352, doi: 10.1007/s00276001-0349-7, indexed in Pubmed: 11824137.

17. Romanes GJ. The abdominal cavity. Cunningham's Manual of Practical Anatomy. Thorax and Abdomen. 5th ed. Oxford University Press, London 2000: 135-136.

18. Romanes GJ. Cunningham's Manual of Practical Anatomy. Thorax and Abdomen. 5th ed. Oxford University Press, London 2004: 137.

19. Sato O, Matsumoto I, Kondoh K. Middle mesenteric artery encountered during abdominal aortic aneurysm surgery. Jpn J Vasc Surg. 2007; 16(7): 799-801.

20. Schoenwolf GC, Bleyl SB, Brauer PR, Fracis-West PH. Development of the gastrointestinal tract.Larsen's Human Embryology, 4th ed. Churchill Livingstone Elsevier, Philadelphia 2009: 441-442.

21. Songür $A$, Toktaş $M$, Alkoç $O$, et al. Abdominal Aorta and Its Branches:Morphometry - Variations In Autopsy Cases. Eur J Gen Med. 2010; 7(3): 321-325, doi: 10.29333/ejgm/82876.

22. Steward JA., Rankin FW. Blood supply of the large intestines: its surgical consideration. Arch Surg. 1933; 26(5): 843-891, doi: 10.1001/archsurg.1933.01170050113008.

23. Tandler J. Zur Entwicklungsgeschichte der menschlichen Darmarterien. Anat Hefte. Beiträge und Referate zur Anatomie und Entwickelungsgeschichte. 1903; 23(1): 188-210, doi: 10.1007/bf02109984.

24. Taniguchi J. Beitrag zur Topographic der grossen Aste der Bauchaorta. Folia Anat Jpn. 1931; 9(3-4): 201-214, doi: 10.2535/ofaj1922.9.3-4_201.

25. Tanuma K, Kitazawa M, Itonaga T, et al. Four cases with the splenic artery of abnormal origin. Kaibogaku Zasshi. 1986; 61(2): 130-137.

26. Williams PL, Bannister LH, Berry MM. Gray's anatomy. 38th ed. Churchill Livingstone, London 1995: 1553-1554.

27. Yoo SJ, Ku MJ, Cho SS, et al. A case of the inferior mesenteric artery arising from the superior mesenteric artery in a Korean woman. J Korean Med Sci. 2011; 26(10): 1382-1385, doi: 10.3346/jkms.2011.26.10.1382, indexed in Pubmed: 22022194. 